Estudios Constitucionales, Año 10, No 2, 2012, pp. 391 - 428.

ISSN 0718-0195

Centro de Estudios Constitucionales de Chile Universidad de Talca

"Cosa Juzgada Constitucional Sui Generis y su Efecto en las Sentencias del Tribunal

Constitucional en materia de Inaplicabilidad e Inconstitucionalidad"

Emilio Alfonso Garrote Campillay

\title{
COSA JUZGADA CONSTITUCIONAL SUI GENERIS \\ Y SU EFECTO EN LAS SENTENCIAS DEL TRIBUNAL CONSTITUCIONAL EN MATERIA DE INAPLICABILIDAD E INCONSTITUCIONALIDAD
}

\author{
ANYTHING DEEMED CONSTITUTIONAL SUI GENERIS AND ITS EFFECT \\ ON THE RULINGS OF THE CONSTITUTIONAL COURT IN TERMS OF NON- \\ APPLICABILITY AND CONSTITUTIONALITY
}

\author{
Emilio Alfonso Garrote Campillay* \\ Profesor de Derecho Constitucional y Administrativo. \\ emilio.garrote@uda.cl.
}

RESUMEN: En el presente trabajo se abordara la cosa juzgada constitucional y su efecto en las sentencias del Tribunal Constitucional, en materia de inaplicabilidad e inconstitucionalidad. Proponemos una cosa juzgada constitucional sui generis o cosa decidida, en atención a las particularidades que presenta esta institución en el ámbito del Derecho Constitucional, por ende no nos ceñiremos al concepto tradicional del Derecho Procesal Civil.

ABSTRACT: In this paper we address the adjudication effect (res judicata) of the Constitutional Court judgments, concerning the unconstitutionality of the law (when it is declared void or strikes down). We propose a sui generis adjudication effect, in consideration of the peculiarities of this institution in the field of Constitutional Law. Therefore we do not restrict ourselves to the res judicata traditional concept of the Civil Procedural Law.

PALABRAS CLAVE: Cosa juzgada - Cosa juzgada constitucional sui generis - Efecto de cosa juzgada en las sentencias de Inaplicabilidad e Inconstitucionalidad.

KEYWORDS: Res judicata - Res judicata sui generis constitutional - Adjudication effect of unconstitutionality judgement.

\section{INTRODUCCIÓN}

Nuestro modelo de justicia constitucional en virtud de la Ley de Reforma Constitucional de 2005, sufrió modificaciones sustanciales. De un sistema

\footnotetext{
* Alumno regular del programa de Doctorado en Derecho de la Universidad de los Andes. Dirección Postal: San Carlos de Apoquindo 2200. Las Condes, Santiago, Chile. Becario Conicyt para estudios de Doctorado en Chile. Email: egarrote@uandes.cl - emilio.garrote@uda.cl. Un agradecimiento especial al profesor de la Facultad de Derecho de la Universidad de los Andes Dr. Luis Alejandro Silva Irarrazabal, por sus observaciones y comentarios. Artículo presentado el 30 de enero de 2012 y aprobado el 20 de junio de 2012.
} 
difuso entregado a la Corte Suprema y Tribunal Constitucional, al decir de algunos autores ${ }^{1}$, o doblemente concentrado según otros ${ }^{2}$; adoptamos un sistema concentrado de control normativo concreto ${ }^{3}$ radicado ahora en el Tribunal Constitucional $^{4}$. Estableciéndose en virtud de la acción de inaplicabilidad un control jurisdiccional concreto, represivo y facultativo de preceptos legales cuya aplicación sea contraria a la Constitución (en adelante CPRCh), y un control abstracto a través de la acción de inconstitucionalidad 5 . Estimo que si bien es concentrado, lo calificaría como impuro, por las razones que expondré más adelante.

En el presente trabajo se analiza la institución de la cosa juzgada constitucional en la CPRCh a partir de la Ley de Reforma Constitucional No 20.050 y sus efectos en materia de control constitucional. Se tomará como base el procedimiento vigente en materia de inaplicabilidad e inconstitucionalidad de acuerdo al artículo 93 numerales 6 y 7, respectivamente. La intención es demostrar que en el ámbito constitucional en general y en el proceso constitucional en particular no podemos aplicar analógicamente la institución de la cosa juzgada tradicional. Pienso que en nuestra disciplina no hay una cosa juzgada constitucional. No al menos en el sentido técnico procesal de la institución. Existe más bien una cosa juzgada constitucional sui generis en atención a las particularidades que presenta, la cual no se corresponde con las características, efectos y finalidades de la cosa juzgada en sentido clásico.

No se pretende en ningún caso agotar la discusión sino muy por el contrario, abrir el debate sobre la materia con la finalidad de determinar los verdaderos efectos y alcances de las sentencias emanadas del Tribunal Constitucional Chileno (en adelante TCCh) en el control constitucional de inaplicabilidad e inconstitucionalidad, dando los primeros matices o ideas bases. El objeto de análisis cobra relevancia dado que se trata del estudio de una materia con escaso tratamiento en nuestra doctrina y legislación, cuya importancia se revela

\footnotetext{
${ }^{1}$ Ríos (2002), p. 40; Martínez (2005), p. 466.

${ }^{2}$ Nogueira (2002), p. 74.

${ }^{3}$ Ríos (2005), p. 76.

${ }^{4}$ Bajo el actual modelo de jurisdicción constitucional, el Tribunal Constitucional tiene potestad para pronunciarse sobre la aplicación de las leyes respecto de gestiones radicadas en tribunales ordinarios o especiales, a objeto de determinar su inaplicabilidad o inconstitucionalidad, pero no tiene facultades para resolver el conflicto o interpretar la ley.
}

5 Zuñiga (2005), p. 490. 
a partir de las nuevas funciones en materia de control constitucional a cargo del TCCh.

Para estos efectos, analizare primero la institución de la cosa juzgada en general. Abordaré luego, la cosa juzgada constitucional sui generis y finalmente tratare sus efectos en las sentencias emanadas del control de inaplicabilidad e inconstitucionalidad.

\section{COSA JUZGADA}

Al hablar de la cosa juzgada podemos hacerlo al menos en dos sentidos. O podemos decir que la expresión admite dos acepciones: cuando se dice que "ya hay cosa juzgada" o "eso es cosa juzgada" hay referencia al estado jurídico en que se encuentran algunas cuestiones o asuntos que han sido objeto de enjuiciamiento de manera definitiva en un proceso. Es decir, el órgano jurisdiccional ha decidido el asunto litigioso de forma irrevocable y definitiva ${ }^{6}$. En una segunda acepción la cosa juzgada hace referencia a determinados efectos de ciertas resoluciones judiciales. La sentencia definitiva se ha pronunciado sobre el objeto del proceso o fondo de la litis. "Es la autoridad y eficacia de una sentencia judicial cuando no existen contra ella medios de impugnación que permitan modificarla" 7 .

Para los fines de esta investigación interesa este último sentido. La cosa juzgada es la calidad que adquieren las sentencias y las resoluciones definitivas de los jueces cuando se han agotado todos los recursos destinados a impugnarlas y se tornan irrevocables. Se trata de una institución jurídica vinculada tradicionalmente a la idea de evitar un pronunciamiento sobre un asunto decidido anteriormente. La sentencia contiene un mandato que cuando adquiere la autoridad de cosa juzgada se torna inmutable. El caso examinado y decidido ya no podrá replantearse con posterioridad conforme al principio "non bis in idem". Quien pretenda realizar un nuevo juicio fundado en el mismo contenido faculta a la contraria para oponer la excepción de cosa juzgada. Este principio es absoluto en el Derecho Penal puesto que la declaración de inocencia es un derecho subjetivo adquirido que no puede ser cuestionado indefinidamente.

${ }^{6}$ De la Oliva (1991), p. 17

${ }^{7}$ Couture (2010), p. 326. 
En cambio, en el proceso civil la sentencia reconoce un derecho patrimonial del cual su titular no podría ser privado sin violarse el derecho constitucional de propiedad. No obstante, en algunos casos se contempla la revisión o rescisión y se acepta la cosa juzgada formal. Esto es, el derecho a promover en un procedimiento posterior la acción tendiente a modificar lo resuelto cuando aparezcan nuevos elementos que no fueron considerados, no siendo posible deducirlo en el mismo proceso. Al respecto, la Corte Suprema ha señalado "la institución de la cosa juzgada, que es una normativa de carácter procesal referente al efecto que deben producir determinadas resoluciones judiciales cuando alcanzan la condición de ser inimpugnables e indiscutibles, tiene como finalidad evitar que vuelva a debatirse entre los interesados el asunto que haya sido objeto de una decisión (...)"8. En otra oportunidad señalo "es nula la sentencia que se pronuncia en contra de otra pasada en autoridad de cosa juzgada, cualquiera sean los errores y defectos de que ésta pueda adolecer"'.

\section{COSA JUZGADA CONSTITUCIONAL}

La Constitución no tiene otro significado jurídico que aquel que le otorgan los jueces en sus sentencias. El Supremo guardián debe interpretar tanto el texto constitucional como el precepto legal sometido a su consideración, pudiendo extraer en su labor interpretativa diversas normas, debiendo decidir por aquella que más se conforme con el Texto Constitucional ${ }^{10}$. El juez constitucional es el centinela de la supremacía y de la fuerza normativa efectiva de la Ley Suprema. El instrumento más eficaz para este cometido es la declaración de inconstitucionalidad. No obstante, no en todos los casos debe recurrir a ella. Debe hacer un esfuerzo por mantener el producto normativo del órgano por esencia democrático, otorgando la máxima certeza del derecho que forma parte del ordenamiento jurídico ${ }^{11}$.

Así lo ha reconocido el propio TCCh al señalar "Tal y como lo han reconocido uniformemente la doctrina y la jurisprudencia comparadas, el respeto hacia la labor que desarrolla el legislador obliga al Tribunal Constitucional, en su función de controlar la constitucionalidad de la ley, a buscar, al menos, alguna

\footnotetext{
${ }^{8}$ Sentencia Corte Suprema, 05 de noviembre de 1970, RDJ, t. 67, sec. 1a, p. 505.

9 Sentencia Corte Suprema, 06 de abril de 1939, RDJ, t. 37, sec. 1a, p. 1.

${ }^{10}$ Nogueira (2004), pp. 112 y ss.

${ }^{11}$ Nogueira (2004), p. 113.
} 
interpretación del precepto cuestionado que permita armonizarlo con la Carta Fundamental y sólo en el evento de no ser ello posible, unido a la necesidad de cautelar integralmente la plena vigencia de los principios de supremacía constitucional, igualdad ante la ley y certeza jurídica, resultará procedente y necesaria la declaración de inconstitucionalidad"12.

La interpretación conciliadora deriva de su fuerza normativa y de su vinculación y cumplimiento inmediato. Es decir, de los principios de constitucionalidad del artículo $6^{\circ}$ de la Constitución ${ }^{13}$. En el considerando decimoséptimo señala "que si bien la sentencia previa de inaplicabilidad es condición del ejercicio de la acción de inconstitucionalidad, esta es examinada y resuelta en su propio mérito y, adicionalmente, exige la calificación de supuestos vinculados al interés público; de manera que, como lo corrobora la historia del proyecto de reforma constitucional reseñada en lo pertinente anteriormente, el Tribunal Constitucional ejercita su atribución facultativamente y no se encuentra obligado a efectuar una declaración de inconstitucionalidad".

A mayor abundamiento, en su sentencia Rol No 1.173, de 16 de abril de 2008, el TCCh sostuvo que, “(...) Debe tenerse presente que la declaración de inconstitucionalidad de un precepto legal declarado inaplicable en sentencia previa no constituye un deber para el Tribunal Constitucional, sino que únicamente una facultad que se ejercerá en la medida que ninguna interpretación del precepto impugnado permita su ajuste con la carta Fundamental" ${ }^{14}$ (considerando cuarto). En otras palabras, la sentencia de inaplicabilidad es sólo una condición o presupuesto para entablar la acción de inconstitucionalidad, no para declararla. La inconstitucionalidad deberá ser examinada y resuelta en su propio mérito, ya que se trata de juicios de legitimidad distintos. La posible inconstitucionalidad del precepto legal se debe realizar sin consideración a situaciones específicas, dado que se trata de un control abstracto; exigiendo la calificación de supuestos vinculados al interés público.

La declaración de inconstitucionalidad en cuanto a su contenido, importa la anulación de la norma legal con efecto general. El TCCh ha señalado que "la declaración de inconstitucionalidad constituye el último recurso, la última ratio para asegurar la supremacía constitucional, dado que implica dejar sin efecto, con carácter derogatorio, un acto emanado del órgano legislativo, expresión

${ }_{12}$ Tribunal Constitucional, Rol No 558 (590)-2006-INC, de 05 de junio de 2007. Rol No 681-2006

13 ZúNiga (2009), p. 16.

${ }^{14}$ Tribunal Constitucional, Rol No 1173-2008-INC, de 16 de abril de 2009. 
de la soberanía popular, lo que eventualmente puede generar un cierto grado de inseguridad jurídica ante el vacío normativo que se produce por la desaparición de un determinado precepto legal que se expulsa del ordenamiento jurídico por ser manifiestamente contrario a la Constitución" 15 . Si bien comparto lo señalado por el Máximo intérprete de la Norma Suprema, considero que es erróneo el efecto derogatorio que le atribuye a la sentencia estimatoria de inconstitucionalidad. En el mismo error incurre el constituyente derivado de 2005 en el artículo 94 inciso tercero, ello porque se trata más bien de un efecto invalidatorio, por las razones que expondremos más adelante.

En esta materia encontramos diversas posiciones doctrinarias. Y así por ejemplo en España Tomás Fernández y Eduardo García, rechazan la aplicación de la cosa juzgada al control abstracto de normas tratándose de la sentencia absolutoria, dado que la institución de la cosa juzgada dice relación con una situación concreta e individualizada. Se basan principalmente en el hecho de que no hay verdaderas partes en el proceso constitucional. Los recurrentes son simples órganos políticos sin personalidad. No hay un conflicto de hecho entre éstas. Además sostienen que sería simplemente una interpretación de la ley. Luego, nunca una sentencia cierra el paso a otra ulterior ya que puede interpretarse la ley de manera distinta ${ }^{16}$. En tanto, para Jordi Nieva "la cosa juzgada consiste simplemente en la prohibición de que los juicios se repitan. Existe para dar fijeza a los juicios ya emitidos y, como consecuencia, seguridad jurídica al sistema jurídico social" ${ }^{\prime 1}$.

En nuestro país se han referido a esta temática los profesores Nogueria, Aldunate, Soto Kloss, Errázuriz y Otero. Humberto Nogueira ${ }^{18}$ y Eduardo Aldunate $^{19}$, sostienen la existencia de una cosa juzgada constitucional, en tanto que Eduardo Soto ${ }^{20}$, Juan Errázuriz y Jorge Otero ${ }^{21}$, aluden a la res judicata secundum eventum litis, a propósito de las sentencias recaídas en la acción de protección. Por último tenemos aquellos que sin entrar a cuestionar la presencia de la cosa juzgada en materia constitucional derechamente sostienen que las sentencias

\footnotetext{
15 Tribunal Constitucional, Rol No 1254-2009-INA, de 29 de julio de 2009.

${ }^{16}$ Fernández y García (1989), p. 186.

${ }^{17}$ Nieva (2010), p. 33.

${ }^{18}$ Nogueira (2005), pp. 421 y ss.

${ }^{19}$ Aldunate (1993), pp. 355 y ss.

${ }^{20}$ Sото (1982), pp. 284-300.

${ }^{21}$ Errazuriz y Otero (1989), pp. 195-2009.
} 
de los tribunales constitucionales producen el efecto de cosa juzgada. Respecto de estos últimos cabe la duda, si se refieren a la cosa juzgada en general o bien es una cosa juzgada distinta, especial, particular. En esta posición encontramos entre otros, a los profesores Patricio Zapata, Lautaro Ríos, Rodrigo Pica y Juan Colombo.

El profesor Patricio Zapata opina que, por razones de seguridad jurídica y contexto constitucional en el caso chileno, las sentencias del TCCh producen el efecto de cosa juzgada. Sus argumentos son:

- Permitir que un mismo asunto vuelva a ser discutido obstaculiza la labor del TCCh en su rol de intérprete supremo de la CPRCh.

- No orientaría la interpretación de los demás tribunales, dejando al resto de los poderes del Estado en una situación de constante incertidumbre ${ }^{22}$. Reconoce la posibilidad de volver a debatir los temas polémicos ante el TCCh, siempre y cuando los órganos interesados proporcionen nuevos argumentos o elementos que justifiquen reabrir la discusión.

Por su parte Lautaro Ríos opina que, tratándose de la sentencia denegatoria de inconstitucionalidad ésta produce cosa juzgada constitucional. Su argumento es, "(...) no puede volver a plantearse eficazmente la inconstitucionalidad del mismo precepto legal por un vicio idéntico al rechazado por aquélla"23.

Rodrigo Pica sostiene que, "las sentencias de inaplicabilidad generan como toda sentencia en general, el efecto de cosa juzgada" 24 . En otro trabajo el mismo autor al tratar los efectos de las sentencias de inaplicabilidad e inconstitucionalidad señala que, "(...) la cosa juzgada constitucional puede ser, además, absoluta o relativa, distinción que incidirá con gran importancia en el sistema de control de constitucionalidad" 25 . Sin embargo, no profundiza sobre el tema.

En tanto Juan Colombo sostiene que, "es de la esencia de todo proceso que los efectos de la sentencia que le pone término se traduzcan en una verdad jurídica indiscutible e inamovible, o sea, que produzca cosa juzgada; que las sentencias emanadas de los procesos que tienen por objeto declarar la inconstitucionalidad de una ley o de un decreto, de competencia de los Tribunales Constitucionales, producen

\footnotetext{
22 Zapata (2008), p. 365.

${ }^{23}$ Ríos (2010), p. 61.

24 PICA (2010a), pp. 254 y ss.

25 PICA (2010b), p. 98.
} 
cosa juzgada sustancial y absoluta, con efecto erga omnes; por lo tanto, lo resuelto no puede volver a debatirse" 26 .

Por mi parte estimo que no existe una cosa juzgada constitucional en el sentido técnico procesal de la institución. Las sentencias emanadas del Tribunal Constitucional no producen cosa juzgada material, sino que en el ámbito constitucional existe una cosa juzgada sui generis. Ésta no responde a las características y principios que fundamentan la cosa juzgada en general. Se aparta de las categorías tradicionales del Derecho en general y del procesal civil en especial, por las razones que pasamos a exponer en el siguiente apartado.

\section{Cosa juzgada Constitucional Sui Generis}

En efecto, en materia constitucional no hay una cosa juzgada en el sentido técnico procesal de la institución objeto de estudio. Estimo que lo que realmente existe es una cosa decidida, y como toda decisión puede ser modificada existiendo fundamentos razonables para ello. Se trata de una cosa juzgada sui generis de acuerdo a los siguientes fundamentos:

\section{a) Vacio normativo}

En relación a la cosa juzgada en materia constitucional existe un vacío normativo. En un primer análisis no es muy difícil darse cuenta que en nuestra CPRCh no hay norma alguna que de manera directa o indirecta, expresa o implícita aluda a institución de la cosa juzgada. Así como tampoco respecto al efecto de las sentencias del TCCh, en materia de inaplicabilidad. Lo mismo puede predicarse respecto de la declaración de inconstitucionalidad. Los efectos de esta última, son consecuencia de la invalidación del precepto legal declarado previamente inaplicable, ahora inconstitucional. El nuevo modelo de justicia constitucional implementado a partir de la Ley de Reforma Constitucional No 20.050 nada dice al efecto. Por su parte la Ley Orgánica Constitucional del $\mathrm{TCCh}^{27}$ nada aporta en la materia.

\footnotetext{
${ }^{26}$ Colombo (2005), p. 285.

${ }^{27}$ Cuyo texto refundido, coordinado y sistematizado se encuentra en el D.F.L. No 5 de fecha 10 de agosto de 2010, del Ministerio Secretaría General de la Presidencia.
} 


\section{b) Dinamismo y flexibilidad}

Las sentencias emitidas en los procesos constitucionales no pueden poseer una rigidez ni producir un efecto que conspire contra la adaptabilidad y dinamismo de la Constitución. Esta última entendida como un orden abierto de reglas y principios. Un marco de posibilidades. Un cauce por el cual discurre el proceso político democrático, que pretende encauzarlo de manera duradera a pesar del carácter cambiante de la realidad subyacente y de las demandas sociales.

\section{c) Jurisprudencia constitucional}

El propio TCCh se abre a la posibilidad de modificar lo resuelto, siempre y cuando la nueva acción se encuentre razonablemente fundada. La sentencia con todo, ha generado cosa juzgada formal. En efecto, el TCCh ha sostenido que no es suficiente que los requirentes mejoren o refuercen una línea argumental para que se pueda volver a examinar un asunto ya discutido. En dicha oportunidad señaló que, "(...) no puede considerarse como razonablemente fundada la acción intentada en la especie, si resulta evidente que el conflicto de constitucionalidad que se plantea por esta Magistratura al conocer del requerimiento de inaplicabilidad, Rol No 468-2006, interpuesto por el mismo señor Pineda Peña en contra de la aplicación del articulo $299 N^{o} 3$, del Código de Justicia Militar, en el proceso judicial en que aquel fue condenado como autor del delito que esa norma establece, por sentencia dictada por el tribunal competente". "(...) la circunstancia referida precedentemente no se altera por el hecho de que ahora se intente por el actor ampliar y complementar el cuestionamiento de fondo ya resuelto por este Tribunal Constitucional, (...)"28.

\section{d) Naturaleza del objeto interpretado}

En materia constitucional en razón de la naturaleza del objeto interpretado amerita la aplicación de reglas singulares. En este sentido compartimos la opinión de la profesora Mariela Rubano. No sólo están en juego intereses patrimoniales, económicos y sociales. Se trata de un cuadro organizado por las

${ }^{28}$ Tribunal Constitucional, Rol No 979-2007-INA, de 29 de noviembre de 2007. 
normas constitucionales que traducen una determinada fórmula política para una estructura social ${ }^{29}$.

\section{e) Finalidad de la jurisdicción constitucional}

Debemos tener presente los fines propios de la jurisdicción constitucional. En especial el control de constitucionalidad de las leyes ${ }^{30}$. Este último va dirigido fundamentalmente a preservar la Supremacía de la Constitución y de manera indirecta o consecuencial, tutelar derechos fundamentales, antes que a cerrar o resolver de manera definitiva un conflicto intersubjetivo ${ }^{31}$. La jurisdicción constitucional es una jurisdicción especialísima, particular. En razón de la norma a operar (Constitución), la finalidad de la operación y el producto de la misma ${ }^{32}$.

No hay un conflicto de fondo cuya solución dependa de la aplicación de las normas, sino que, el conflicto mismo se subsume en la pretensión de aplicación de la norma constitucional (inaplicabilidad de un precepto cuyos efectos sean contrarios a la Ley Fundamental o la invalidación de una norma previamente declarada inaplicable). Se trata de un derecho específico, de carácter político, justificada en el mismo como cúspide de la jerarquía normativa, como defensora de esa ubicación. Dando como resultado, la exigencia de vigencia general, la que viene a sustituir la inmutabilidad propia del producto de las demás jurisdicciones ${ }^{33}$.

\section{f) Legislación extranjera y cosa juzgada}

El control de constitucionalidad conserva una autonomía de fin frente al que es inherente al proceso en que la sentencia es dictada. Aun en el ámbito del control difuso de la constitucionalidad, en aquellos sistemas difusos o mixtos de jurisdicción constitucional, o de la cuestión de inconstitucionalidad, en los que la determinación de la compatibilidad de una norma legal con la Constitución se produce a partir de un litigio concreto, como paso previo para su resolución.

\footnotetext{
${ }^{29}$ Rubano (1997), p. 110.

${ }^{30}$ Véase Tribunal Constitucional, Rol No 591-2006-RINC, de 11 de enero de 2007.

${ }^{31}$ Casal (2004), p. 306.

32 Aldunate (1993), p. 355.

${ }^{33}$ Aldunate (1993), pp. 355-359.
} 
En este tipo de control las exigencias de la seguridad jurídica ostentan una intensidad menor a la que es característica en los procesos ordinarios. Ya que prevalece el interés en salvaguardar la Constitución, con todo lo que ello implica ${ }^{34}$. Sin embargo, en procesos constitucionales como en el caso del Amparo, los requerimientos de la seguridad jurídica no son muy distintos de los propios del proceso civil ${ }^{35}$. En efecto, tratándose del amparo junto con garantizar un derecho fundamental, se encuentran intereses subjetivos que reclaman una solución del conflicto jurídico constitucional. No obstante, la cosa juzgada igualmente ofrece particularidades y en ningún caso implica una petrificación de la interpretación constitucional que sirvió de fundamento a la sentencia ${ }^{36}$.

En los sistemas de control concentrado de constitucionalidad en el derecho comparado, los procesos de control normativo son por lo general básicamente dos. La acción directa de inconstitucionalidad de las leyes, que permite impugnar ante el Tribunal Constitucional la ley considerada contraria a la Constitución y la cuestión de inconstitucionalidad, en virtud de la cual los jueces deben someter a la consideración de tal tribunal la posible inconstitucionalidad de una norma legal relevante para la resolución de un caso concreto. La aceptación rigurosa de una cosa juzgada material en tales procesos impediría replantear ulteriormente el asunto decidido, en cuanto concierne a la constitucionalidad o inconstitucionalidad del precepto impugnado ${ }^{37}$.

En algunos sistemas se permite incluso la interposición de una nueva acción directa basada en los mismos argumentos antes rechazados, o la elevación por otro juez, en la misma causa (juez de alzada, por ejemplo) o en una distinta, de una cuestión de inconstitucionalidad en relación con el precepto ya impugnado o cuestionado y con base en razones semejantes.

Así nos encontramos que en algunos sistemas de manera expresa se declara que las sentencias estimatorias emanadas del control de constitucionalidad no

\footnotetext{
34 Casal (2004), p. 307.

35 Por ejemplo en España, donde además de los procesos de amparo ante los tribunales ordinarios, existe el recurso de amparo ante el Tribunal Constitucional y el habeas corpus.

${ }^{36}$ En Venezuela las sentencias de tutela o de amparo dictadas por los tribunales son objeto de revisión extraordinaria por la Sala Constitucional del Tribunal Supremo, lo mismo sucede en Colombia, quedan sujetas a la revisión por parte de la Corte Constitucional.

37 Casal (2004), p. 308.
} 
producen cosa juzgada, como en el caso de la Jurisdicción Constitucional de Costa Rica, el artículo 87 de la ley de la Jurisdicción Constitucional dispone que las sentencias desestimatorias de la inconstitucionalidad no producen cosa juzgada ${ }^{38}$. En otros sistemas se morigera el efecto de cosa juzgada, como sucede en Colombia en que las sentencias de la Corte Constitucional hacen tránsito a cosa juzgada constitucional, de acuerdo a lo dispuesto por el artículo 243 inciso primero de la Constitución ${ }^{39}$.

Otros sistemas se hacen alusión al efecto de las sentencias constitucionales más no a la cosa juzgada, por ejemplo, la Constitución en Perú prescribe que la sentencia estimativa de inconstitucionalidad se publica en el diario oficial y al día siguiente dicha norma queda sin efecto, sin retroactividad, de acuerdo a lo dispuesto en el artículo $204^{40}$. La Constitución de Ecuador al efecto señala en su artículo 278 "La declaración de inconstitucionalidad causará ejecutoria y será promulgada en el Registro Oficial. Entrará en vigencia desde la fecha de su promulgación $y$ dejará sin efecto la disposición o el acto declarado inconstitucional. La declaratoria no tendrá efecto retroactivo, ni respecto de ella habrá recurso alguno".

La Constitución Federal alemana prescribe en su artículo 94.2 que "Una ley regulará la composición y el procedimiento del Tribunal y determinará en qué casos sus decisiones tendrán fuerza de ley. Dicha ley podrá disponer que para los recursos constitucionales sea condición necesaria el agotamiento previo de la vía judicial, asi como prever un procedimiento especial de admisión de los asuntos". La Constitución italiana en su artículo 136 dispone que "Cuando la Corte Constitucional declare la inconstitucionalidad de una disposición legislativa o de algún acto con rango de ley, la norma dejará de surtir efecto desde el día siguiente al de la publicación de la sentencia". En cambio, la Constitución española de 1978 constituye una excepción en la materia. No sólo se refiere expresamente al carácter vinculante de las sentencias constitucionales, sino también, al efecto de cosa juzgada, en su artículo $164^{41}$.

\footnotetext{
${ }^{38}$ Hernández (2004), pp. 45-60.

39 "Los fallos que la Corte dicte en ejercicio del control jurisdiccional hacen tránsito a cosa juzgada constitucional".

40 "La sentencia del Tribunal que declara la inconstitucionalidad de una norma se publica en el Diario Oficial. Al día siguiente de la publicación dicha norma queda sin efecto.

No tiene efecto retroactivo la sentencia del Tribunal que declara inconstitucionalidad, en todo o parte una norma legal".

41 "Las sentencias del Tribunal Constitucional se publicaran en el Boletín Oficial del Estado con los votos particulares, si los hubiere. Tiene el valor de cosa juzgada a partir del día siguiente de su publicación y
} 
Las peculiaridades de la cosa juzgada constitucional van más allá de lo permitido por dicho concepto. Así ocurre con las sentencias desestimatorias de la inconstitucionalidad, cuando se permite sin limitaciones un nuevo examen de la validez constitucional de la ley, o cuando ello es posible si ha ocurrido una variación no en los hechos, sino en las ideas jurídicas o sociales prevalecientes. Además, aun en los supuestos en que el replanteamiento de una acción o cuestión de inconstitucionalidad referida a la misma ley y a idénticos preceptos constitucionales se supedita a la presentación de otros argumentos. Su admisión rompe con los moldes de la cosa juzgada. Ésta no resulta enervada por un simple cambio en la argumentación del accionante, si se mantiene la identidad de sujetos, de objeto y de título jurídico.

Por todo lo anterior, comparto la opinión de los profesores Tomás Fernández y Eduardo García quienes sobre la materia en estudio han sostenido que tratándose del control abstracto de normas resulta aún más cuestionable la existencia de la cosa juzgada. Donde no hay verdaderas partes, dado que los recurrentes son simples órganos políticos sin personalidad. No hay un conflicto de hecho entre éstas. No puede aplicarse a la sentencia absolutoria la institución en análisis, ya que ésta dice relación con una situación concreta e individualizada. Sería simplemente una interpretación de la ley. Luego, nunca una sentencia cierra el paso a otra ulterior, ya que puede interpretar la ley de manera distinta ${ }^{42}$. Y es que, como señala el profesor Francisco "(...) el Tribunal Constitucional, como órgano de control de constitucionalidad, ejerce una jurisdicción de naturaleza juridica y orgánica que, con competencias ajenas a decisiones sobre conflictos de intereses particulares o a casos concretos con contradictorios propios de la jurisdicción ordinaria"¥3.

\section{g) Falta de coordinación entre judicaturas}

No existe una debida correspondencia entre la judicatura ordinaria y la jurisdicción constitucional. El tribunal a quo al resolver el juicio de fondo en caso alguno hace alusión en los considerando de su fallo, a las consideraciones adoptadas por el TCCh en sus sentencias. Incluso en aquellos casos en que

\footnotetext{
no cabe recurso alguno contra ellas. Las que declaran la inconstitucionalidad de una ley o de una norma con fuerza de ley y todas las que no se limiten a la estimación subjetiva de un derecho tienen plenos efectos frente a todos".

42 Fernández y García (1989), p. 186.

43 ZúNiga (2010), p. 267.
} 
ha sido el propio tribunal de la gestión pendiente quien ha solicitado el pronunciamiento del TCCh, sea éste ordinario o especial. Comparto la opinión del profesor Sergio Verdugo en el sentido de que nuestro modelo de control constitucional separado del poder judicial carece de reglas de jerarquía claras, no existiendo normativas que regulen de manera eficiente las relaciones entre el TCCh y el Poder Judicial, especialmente con los tribunales superiores de justicia ${ }^{44}$ y así por lo demás ha quedado de manifiesto en sentencias recientes de la Corte Suprema en relación a las Sentencia de la Corte de Apelaciones de Valparaíso y del Tribunal Constitucional ${ }^{45}$.

\section{b) Autonomía de la decisión constitucional}

Los efectos de las sentencias del TCCh no se producen respecto de la gestión pendiente, sino sólo en el proceso constitucional propiamente tal. En efecto, el TCCh no está facultado para señalarle al tribunal a quo que norma debe aplicar, sólo le puede indicar en virtud de la sentencia estimatoria de inaplicabilidad, que norma no deberá aplicar. En otras palabras y como expresamente lo ha reconocido el TCCh, la declaración de inaplicabilidad genera un efecto negativo "el efecto exclusivamente negativo de la declaración de inaplicabilidad traducido en que, declarado por esta Magistratura que un precepto legal preciso es inaplicable en la gestión respectiva, queda prohibido al tribunal que conoce de ella, aplicarlo" 46.

Ahora, desestimada una inaplicabilidad el juez de fondo recupera plenamente su competencia para pronunciarse sobre el objeto de la litis, sobre el fondo. A él le corresponde determinar la norma que aplicará a la resolución del caso sometido a su conocimiento, la que no necesariamente será la misma cuya constitucionalidad fue cuestionada sin éxito ${ }^{47}$. En otras palabras, siempre la competencia para pronunciarse sobre el fondo de la litis la tiene el juez

\footnotetext{
${ }^{44}$ Verdugo (2011), p. 1.

45 Sentencia Corte Suprema, Rol No 4518-2011, de 30 de noviembre de 2011. Sentencia Corte Apelaciones Valparaíso Rol No 300-2010, de fecha 06 de mayo de 2011, Tribunal Constitucional, Rol No 1801-2010-INA, de 12 de abril de 2011.

${ }^{46}$ Tribunal Constitucional, Rol No 608-2006- INA, de 02 de octubre de 2007 - Rol No 623-2006- INA, de 10 de septiembre de 2007.

${ }^{47}$ Tribunal Constitucional, Rol No 781-2007- INA, de 27 de septiembre de 2007 - Rol No 535-2006INA, de 8 de mayo de 2007.
} 
a quo, la que se suspende transitoriamente en el evento que se plantee una inaplicabilidad si así lo determina la sala que conoce sobre la admisibilidad de la acción. En tanto el TCCh no tendría competencia para pronunciarse sobre la cuestión de fondo.

Sin embargo como se trata de la aplicación de un precepto legal cuyos efectos sean contrarios a la Ley Suprema, este enjuiciamiento lo puede realizar el TCCh no sólo mientras está pendiente la dictación de la sentencia definitiva, sino también estando pendiente la revisión de ésta, lo que sucede por ejemplo, en sede de apelación. En este último caso ya hay un pronunciamiento por parte de un tribunal y una de las partes ha recurrido en contra de la decisión y habiéndose iniciado el conocimiento del recurso, la parte recurrente o el tribunal que conoce del recurso, plantea la cuestión de inaplicabilidad. Así las cosas, la inaplicabilidad se transforma en un mecanismo de control de la interpretación y aplicación de preceptos legales a un caso concreto ${ }^{48}$. En el mismo sentido se pronuncia Gastón Gómez ${ }^{49}$.

\section{i) Naturaleza incidental}

Si se analiza la cuestión desde el punto de vista procedimental, el proceso constitucional debiera constituir un incidente respecto de la gestión pendiente. En tanto es de la esencia de la cosa juzgada que la sentencia que adquiere dicha calidad resuelva el asunto, el objeto del proceso. En definitiva que se pronuncie sobre el fondo de la litis. Si bien la inaplicabilidad la podemos calificar como acción, a diferencias de las acciones en general, ésta tiene una dependencia directa de la gestión pendiente. Da origen al proceso constitucional de inaplicabilidad, pero lo hace a propósito de una gestión pendiente. Luego, la sentencia pareciera que no produce cosa juzgada al no pronunciarse sobre el fondo como sucede en materia de acciones procesales. Entendida esta última como derecho público subjetivo destinada a provocar el ejercicio de la actividad jurisdiccional para la aplicación del derecho a un caso concreto con eficacia de cosa juzgada ${ }^{50}$.

\footnotetext{
${ }^{48}$ Martínez (2011), p. 383.

49 Gómez (2005), p. 669.

${ }^{50}$ Romero (2002), p. 23. Ha sostenido que: "Para que las sentencias interlocutorias firmes produzcan cosa juzgada, se debe exigir un pronunciamiento sobre el fondo del asunto o sobre alguna situación jurídica equiparable al pronunciamiento sobre el fondo".
} 


\section{j. Cosa juzgada formal}

Con todo, las sentencias emanadas del control constitucional de inaplicabilidad por parte del TCCh sólo producirían cosa juzgada formal en el evento que acoja la pretensión. La posibilidad de revisar a través de recursos lo decidido mediante sentencia resulta por regla general descartada en atención al rango del órgano jurisdiccional que la emite, cuyo pronunciamiento no son impugnables, pero es mutable mediante sentencia dictada en juicio diverso. En los sistemas que autorizan a los jueces ordinarios para conocer de tales procesos o para ejercer el control (difuso) de constitucionalidad de las leyes, el agotamiento o la falta de interposición de los recursos disponibles producen el mismo efecto. Sin perjuicio de los poderes extraordinarios de revisión de sentencias que ostenta la máxima instancia de la justicia constitucional ${ }^{51}$.

Ahora si la acción de inaplicabilidad es desestimada sin duda no genera cosa juzgada, de manera que puede volver a plantearse la inconstitucionalidad, máxime si consideramos que lo que se declara inaplicable no es la norma misma, sino la interpretación del precepto legal que provoca efectos contrarios a la Constitución. En definitiva en el caso de la inaplicabilidad son hipótesis de inconstitucionalidad que plantean las partes o el juez al TCCh, perfectamente puede suceder que las partes plantean una inaplicabilidad respecto de la aplicación de un precepto legal que jamás estuvo en la mente del juez del fondo aplicarlo a la gestión pendiente, en cuyo caso la decisión del intérprete Constitucional será inoficiosa.

\section{k. Efecto negativo y positivo de la cosa juzgada}

La declaración de inconstitucionalidad genera la invalidez del precepto legal declarado previamente inaplicable. Es sabido que la cosa juzgada genera acción y excepción. Tratándose de la declaración de inconstitucionalidad no podría ser alegada ya que la norma no es parte del ordenamiento jurídico. Sin duda alguna ya no podría discutir en juicio lo resuelto en la sentencia. Pero ello no es producto del efecto de cosa juzgada, sino por el efecto del control abstracto. Dicho en otras palabras y de acuerdo al planteamiento sostenido, por el efecto sui generis de la cosa juzgada constitucional. Si efectivamente se vuelve a plantear el asunto sería un problema de Iura novit curia.

51 Casal (2006), pp. 243 y ss. 
En consecuencia, como hemos podido apreciar la cosa juzgada en el ámbito constitucional posee características propias, distintas a las que tradicionalmente se le han atribuido en el derecho, en particular en materia procesal civil. En este aspecto comparto la opinión del profesor Eduardo Aldunate ${ }^{52}$. En el mismo sentido, el profesor Juan Colombo ha señalado "los efectos erga omnes que se atribuyen a las sentencias recaidas en los procesos de inconstitucionalidad, ponen de manifiesto, prima facie, la imposibilidad de aplicar a este tipo de sentencia los principios procesales comunes respecto de los efectos de las sentencias" 53 . En la práctica, los efectos de las sentencias emanadas del control en materia de inaplicabilidad e inconstitucionalidad quedan en gran medida determinados por la forma en que los tribunales cumplen las sentencias. Es decir, si consideran o no las decisiones del TCCh.

\section{EFeCTO de COSA JUZGADA SUI GENERIS EN LAS SENTENCIAS DE INAPLICABILIDAD E INCONSTITUCIONALIDAD}

Para poder entender de mejor manera las particularidades de esta cosa juzgada sui generis, o cosa decidida, previamente realizaré algunas observaciones al nuevo modelo de justicia constitucional implementado a partir de la reforma de 2005. Se dará cuenta en términos generales del tratamiento a nivel de doctrina de los efectos de las sentencias emanadas del control constitucional. Se analizan algunas instituciones muy cercanas a la cosa juzgada, destacando sus diferencias, como por ejemplo, la preclusión, la inadmisibilidad y el precedente constitucional. Finalmente me aboco a los efectos de cosa juzgada sui generis en las sentencias emanada del control constitucional nacional a propósito de la acción o cuestión de inaplicabilidad e inconstitucionalidad.

Para algunos autores es de la esencia de todo proceso que los efectos de la sentencia que le pone término se traduzcan en una verdad jurídica indiscutible e inamovible, o sea, que produzca cosa juzgada. Que las sentencias emanadas de los procesos que tienen por objeto declarar la inconstitucionalidad de una ley o de un decreto de competencia de los Tribunales Constitucionales producen cosa juzgada sustancial y absoluta, con efecto erga omnes. Por lo tanto, lo resuelto no puede volver a debatirse ${ }^{54}$. El propio TCCh sobre la materia no ha tenido

\footnotetext{
52 Aldunate (1993), p. 356.

${ }^{53}$ Colombo (2002), p. 66.

${ }^{54}$ Colombo (2005), p. 285.
} 
un criterio uniforme. Éste no alude a la cosa juzgada, sino que utiliza otros términos para referirse a ella. Como por ejemplo, declaración de inadmisibilidad, preclusión. En otros casos atiende a la naturaleza del proceso constitucional como tendremos la oportunidad de analizar más adelante.

\section{a) Control concentrado e impuro}

Como adelantaba al comienzo de este trabajo, estimo que si bien el nuevo modelo de justicia constitucional podría calificarse como concentrado, debe ser considerado como "impuro", básicamente por dos razones:

1. El tribunal Constitucional no es el intérprete exclusivo y excluyente de la Ley Fundamental. Nuestro control constitucional está radicado en distintos órganos. En algunos casos de manera directa y en otros indirectamente. De manera indirecta en las Cortes de Apelaciones tratándose de la acción de protección y recurso de amparo. En la Contraloría General de la República por vía de la Toma de Razón de actos administrativos. En la Corte Suprema como tribunal de segunda instancia en el caso de la acción de protección y amparo. El Senado cuando se pronuncia sobre la acusación constitucional. Pero principalmente y de manera directa en el Tribunal Constitucional cuando se trata de los controles en materia de inaplicabilidad e inconstitucionalidad de las normas.

2. A diferencia de lo que sucede en el derecho comparado, nuestra acción de inconstitucionalidad es dependiente de la cuestión o acción de inaplicabilidad. Sólo se puede invalidar aquellos preceptos legales declarados previamente inaplicables. Sin embargo, ambos institutos son totalmente distintos en su naturaleza y efectos. Lo único que tienen en común es el hecho que la inaplicabilidad es un requisito procesal de la inconstitucionalidad.

También contribuye a la impureza de este sistema concentrado, que tanto el juez como las partes de la gestión pendiente están habilitadas para requerir directamente el pronunciamiento del TCCh a diferencia de lo que sucede en el caso italiano o español donde no existe la inaplicabilidad. Las partes le plantean la duda de inconstitucionalidad al juez a quo. Es éste quien en último término decide si requiere o no el pronunciamiento del Intérprete Supremo. Actuando como una especie de filtro del sistema de control.

\section{b. Efectos de las sentencias constitucionales}

La determinación de los efectos de las sentencias constitucionales no es pacífica, tanto a nivel nacional como en la experiencia comparada. Ha dado 
lugar a innumerables controversias que inclusive han cuestionado la aplicabilidad en este ámbito de las categorías ordinarias del Derecho Procesal. El tratamiento en el derecho comparado y en la doctrina no es en modo alguno uniforme, lo que complica su análisis y exposición ${ }^{55}$. En algunos sistemas la jurisprudencia tiende a comprender los principales efectos de las sentencias constitucionales bajo el concepto de la cosa juzgada. Así se observa en los pronunciamientos de la Corte Constitucional colombiana, y en parte hasta fecha reciente en Venezuela. Mientras que en otros se distingue el efecto vinculante, la cosa juzgada y la fuerza de ley o eficacia general ${ }^{56}$.

Asimismo, juega un papel relevante la noción de precedente constitucional que ha sido utilizada en distintos ordenamientos. Incluso en países con tradición jurídica romano-canónica (civil law $)^{57}$. Este trabajo nos permitirá, sin ánimo de ser exhaustivos y de agotar la discusión, destacar las peculiaridades de la cosa juzgada en la jurisdicción constitucional. Sobre todo en los procesos de control normativo. Cuestión no menor, ya que determinar los verdaderos efectos de las sentencias del Intérprete Constitucional resulta relevante a la hora de conjugar los imperativos de seguridad jurídica con la apertura de la Constitución a las cambiantes exigencias de la realidad política y social.

\section{c) Preclusión y cosa juzgada}

El término preclusión proviene del latín praeclusio, praeclusionis, que tiene su explicación en la propia naturaleza del juicio y que según el Diccionario de la Real Academia Española, haciendo eco de la citada naturaleza, alude a aquél "carácter del proceso, según el cual el juicio se divide en etapas, cada una de las cuales clausura la anterior sin posibilidad de replantear lo ya decidido en ella" ${ }^{\prime 2}$. Es un error pretender asimilar la cosa juzgada con la preclusión. Esta última es una institución procesal que permite ir cerrando las distintas etapas del proceso. Una vez trascurrido el plazo previsto para realizar una actuación procesal ya no es posible realizarla. Entonces decimos que ha precluido la posibilidad de realizar válidamente dicha actuación. Así la preclusión tiene

55 CASAL (2004), p. 300

56 LÓpez (2000), pp. 14 y ss.

57 Véase Legarre y Rivera (2006), pp. 109 y ss.

58 Véase Diccionario de la Real Academia de la Lengua Española, vigésima segunda edición 2001. 
relevancia durante el proceso, en cambio la cosa juzgada se genera o produce al término del proceso. Cuando se dicta una sentencia que adquiere el carácter de firme y ejecutoriada.

Otros autores entienden por preclusión la extinción en un concreto proceso de los poderes jurídico-procesales no ejercitados por los sujetos que intervienen o pueden intervenir en el proceso ${ }^{59}$. Para otros la preclusión es ese efecto derivado del transcurso de los plazos y de la finalización de los términos previstos para la realización de los actos. Que consiste en impedir aquellos que no se hubiesen realizado o en convertirlos en completamente ineficaces si se llevasen a cabo fuera de plazo o transcurrido el término ${ }^{60}$. La Corte Suprema define la preclusión "como la pérdida, extinción o caducidad de una facultad procesal (...)" ${ }^{61}$. Por lo antes señalado queda demostrado que cosa juzgada y preclusión son dos instituciones totalmente distintas. Lo único que tienen en común es su naturaleza procesal ${ }^{62}$.

Como ya lo había anticipado, la preclusión actúa durante el proceso. En tanto, la cosa juzgada opera al término del proceso. Emana de la sentencia una vez que ésta se encuentra firme y ejecutoriada. Así, por lo demás lo ha reconocido el TCCh al señalar "Que, aun cuando la preclusión y la cosa juzgada son institutos procesales vinculados, son diferentes y autónomos (...)"63. El TCCh conecta la institución en análisis con las garantías del debido proceso y la seguridad jurídica en su considerando decimosegundo, para fundar su decisión" (...) Que, en consecuencia, debe concluirse que en el proceso que constituye la gestión pendiente este es el segundo requerimiento de inaplicabilidad por inconstitucionalidad interpuesto por la misma materia y fundamento, por lo cual debe ser desestimado, toda vez que al haber consumado en el requerimiento anterior su derecho, éste precluyó" 64 .

59 Vallines (2004), p. 33.

${ }^{60}$ Muerza et al. (2001), p. 605.

${ }^{61}$ Sentencia Corte Suprema, Rol No 12.684, de 4 de mayo de 1990.

${ }^{62}$ La confusión emana de la máxima según la cual la cosa juzgada cubre lo deducido y lo deducible, la sola expresión cosa juzgada, demuestra que la máxima es errática, en efecto, resulta un contrasentido afirmar que hay cosa juzgada sobre "lo no juzgado". Técnicamente es más correcto sostener que hay cosa juzgada sobre lo deducido y juzgado, en tanto que, sobre lo no deducido y, por ende, no juzgado, pero deducible, existe preclusión.

${ }^{63}$ Tribunal Constitucional, Rol No 1311-2009- INA, de 2 de abril de 2009.

${ }^{64}$ Tribunal Constitucional, Rol No 1311-2009- INA, de 2 de abril de 2009. 
La preclusión constituye una limitación jurídica, el acto podría realizarse fácticamente, pero la posibilidad jurídica se ve coartada. “(...) Se trata de una pérdida o extinción, pues el ejercicio del poder de que se trate, mediante la realización del acto o diligencia, es lo que acarrearía lo que se pretende evitar: la contradicción de actos, el retroceso, la repetición o la ambigüedad en la discusión"65.

\section{d) Inadmisibilidad y cosa juzgada}

En cuanto a la inadmisibilidad habrá que atender a la naturaleza jurídica de la resolución que desestima una acción o cuestión de inaplicabilidad o de inconstitucionalidad para ver si produce o no cosa juzgada, pero en ningún caso son términos sinónimos o asimilables. Lo que si resulta interesante en este punto es la problemática que se suscita al pretender plantear nuevamente el asunto cuando hay declaración de inadmisibilidad. Dado que el examen que se efectúa es más bien de forma, sin entrar al fondo del asunto discutido. Sin embargo nuestro Tribunal ha tenido criterios dispares, en algunos casos ha aceptado los nuevos requerimiento y en otros no, más no se funda en la existencia o inexistencia de cosa juzgada para su decisión.

En efecto, el TCCh para determinar si procede o no la acción de inaplicabilidad respecto de aquellos casos en que hubo un requerimiento de inaplicabilidad que fue declarado inadmisible y versa sobre la misma materia, realiza un examen distinto a la admisibilidad, recurriendo a la institución de la preclusión. Así ha señalado "Que para decidir la procedencia de esta segunda inaplicabilidad, esta Magistratura debe resolver si es constitucionalmente lícito plantear en una gestión pendiente más de un requerimiento respecto de la misma materia. (...) Para ello resulta determinante analizar la institución procesal de la preclusión en el sistema procesal nacional y cómo opera en este proceso constitucional"'66.

En la especie, siguiendo en la materia a Eduardo Gandulfo estamos frente a uno de los supuestos operativos de la preclusión, esto es, preclusión por consumición. "(...) una vez que se ha ejercido una facultad procesal, presentado un recurso especifico, un medio de prueba particular, un acto defensivo de su posición, sea que lo gane parcialmente o le sea rechazado (...) para que no vuelva a repetirse lo ya promovido, y volver atrás en el proceso, o para que no se pueda modificar lo

${ }^{65}$ Gandulfo (2009), p. 131.

${ }^{66}$ Tribunal Constitucional, Rol No 1311-2009 INA, de 2 de abril de 2009. 
promovido, volviendo a plantear más temas o variar los ya presentados, sorprendiendo a la contraria que ya ventiló su defensa, la parte que ya presentó el medio, pierde la facultad para volver hacerlo o modificarlo, porque desde el punto de vista de la preclusión ya consumió su facultad al presentar previamente dicho medio" 67.

\section{e) Precedente constitucional y cosa juzgada}

En los países anglosajones impera un sistema jurídico denominado Stare Decisis, lo que implica un respeto por las decisiones precedentes. Esto es, por las decisiones tomadas previamente por otros tribunales que resolvieron un problema semejante. Debe estarse a lo decidido y no perturbar lo ya establecido, lo que está quieto "Stare decisis et quieta non movere" 68 . Sin embargo, no todo el contenido de los casos anteriores es vinculante, no todo lo incluido en la sentencia constituye un precedente. Así se alude a la ratio decidendi del caso, esto es, la razón para decidir. En otras palabras la razón o razones que tuvo un tribunal para decidir un caso de determinada manera. Humberto Nogueira opina que, "es la parte del fallo que fundamenta directa e inmediatamente el precedente. Estableciendo la regla o principio que define el tribunal al resolver el problema o caso sometido a su consideración"69. Aquí estaría la fuerza o valor de precedente.

En los Estados Unidos de Norteamérica se utiliza la expresión holding. En ambos casos, ratio decidendi y holding, se utilizan en contraposición de la expresión obiter dictum. Es decir lo expresado por un tribunal incidentalmente "dicho sea de paso". Lo manifestado en una sentencia pero que resulta innecesario para la decisión del caso. Ya sea por referirse a hechos hipotéticos o a una situación de hecho distinta. $\mathrm{O}$ argumentos jurídicos no obstante pertinentes resultan superfluos para la decisión ${ }^{70}$. Lo que no genera precedente, no tiene valor obligatorio para los casos futuros. Actualmente el sistema judicial de Estados Unidos se desenvuelve bajo una doctrina del precedente jerarquizado, pero flexible. Pudiendo los tribunales superiores vincular con sus decisiones a los inferiores. Pero deben ser igualmente receptivos a los cambios sociales y al dinamismo de los casos que se presenten en las instancias inferiores.

\footnotetext{
${ }^{67}$ Gandulfo (2009), p. 179.

${ }^{68}$ Legarre y Rivera (2006), p. 109.

69 Nogueira (2006), p. 169.

${ }^{70}$ Nogueira (2006), pp. 119-121.
} 
La Corte Suprema y los jueces pueden interpretar la Constitución. Originando argumentos constitucionales que no pueden ser contradecidos por un legislador. Luego, las decisiones de los jueces norteamericanos alcanzan valor de precedente constitucional vinculante, constituyendo de esta forma una Fuente del Derecho. En países como el nuestro, de tradición jurídica continental no existe la doctrina del precedente. Con todo la jurisprudencia adquiere importancia cuando una determinada solución se repite en el tiempo y genera una costumbre. Sin embargo, en el último tiempo se ha observado una tendencia a la convergencia entre el sistema del common law y civil law. Cuestión que también puede predicarse respecto del rol que ha adquirido la jurisprudencia como fuente del derecho. En el caso nuestro esta tendencia se puede observar en materia procesal penal, laboral y en el mensaje del proyecto de Código Procesal Civil, en tramitación en el congreso desde el año $2009^{71}$.

Independiente del sistema jurídico los casos similares tienden a ser resueltos similarmente. Sin embargo, el sistema inglés del precedente se caracteriza por su fuerte naturaleza coercitiva. Un solo precedente obliga, en cambio en el civil law, la jurisprudencia tiene fuerza persuasiva. No siendo en general reconocida como fuente del derecho. Luego, no genera obligación jurídica. Existe una preeminencia de la ley opacando a la jurisprudencia. Lo que en parte se puede explicar por la distinción entre fuentes formales donde sobresale la ley y fuentes materiales en las que se incluye la jurisprudencia. La jurisprudencia puede ser utilizada para resolver un nuevo caso. En cambio, en los países del common law los jueces están obligados a resolver conforme al precedente aplicable al caso en cuestión.

Se denomina Precedente Constitucional a la fuerza vinculante que tienen las sentencias de los Tribunales Constitucionales, cuyos fallos no se limitan a la mera declaración de inconstitucionalidad o constitucionalidad de una norma concreta. Sus efectos deben ir más allá. Modelando el comportamiento de todos los órganos del Estado. En especial sobre los poderes colegisladores. Sobre las decisiones que adopta la justicia ordinaria en el contexto de un Estado Constitucional y democrático de Derecho ${ }^{72}$. En opinión del profesor Miguel Ángel Fernández "el precedente es la decisión contenida en una sentencia y la interpretación de la o las normas que le sirven de base directa, la cual debe ser repetida cuando se

${ }^{71}$ Romero (2011), pp. 932-933.

72 Carreño y Jaraquemada (2010), p. 408. 
aplica a un caso análogo o donde se deben considerar las mismas normas, salvo que el Tribunal que lo dictó lo enmiende fundadamente"73.

En un orden político y social el precedente permite dar consistencia y previsibilidad a la interpretación del ordenamiento jurídico constitucional y cumplir con los estándares de razonabilidad y universalidad en la aplicación del Texto Constitucional. Contribuyendo a la certeza jurídica, así conjuntamente con la cosa juzgada tendríamos también una cosa interpretada ${ }^{74}$. El profesor Humberto Nogueira, comentando el Proyecto de Reforma Constitucional materializado en la Ley No 20.050, participa de la idea de establecer que la ratio decidendi debería ser al menos criterio auxiliar para la aplicación del derecho por todos los órganos del Estado. Mientras dichos criterios no sean modificados por el TCCh. Distinguiéndose de los obiter dicta, los que no tienen el mismo carácter. Por lo que no constituyen precedentes. Ni deben ser seguidos por los tribunales inferiores ${ }^{75}$.

Sin embargo, no debemos confundir este efecto con el de cosa juzgada. El efecto de cosa juzgada implica que la certeza declarada en la sentencia impide una decisión de fondo sobre el mismo juicio. Tampoco debemos confundirlo con los efectos emanados de la parte resolutiva de la decisión adoptada. O con el efecto erga omnes de la declaración de inconstitucionalidad que provoca la invalidación de la norma viciada y que obliga a toda persona, grupo y órgano del Estado. No obstante, el precedente participa de la cosa juzgada de la que goza la parte resolutiva de la sentencia y se beneficia del efecto erga omnes del fallo de inconstitucionalidad.

Discrepo de la doctrina nacional que al hablar del sentido y alcance de la interpretación constitucional o efecto de los fallos del TCCh lo hacen utilizando la expresión precedente constitucional, especialmente en el caso de la inaplicabilidad. Dado que en el caso de la inconstitucionalidad, los efectos se producen por la invalidación de la norma del sistema jurídico. El precedente constitucional implica que las decisiones del órgano de justicia constitucional son de observancia obligatoria para los distintos poderes públicos y los ciudadanos. En el Sistema Anglosajón o del Common Law los tribunales y jueces inferiores en el caso inglés, se encuentran sometidos rígidamente a los precedentes judiciales. Constituyéndose así en una verdadera Fuente del Derecho.

\footnotetext{
${ }^{73}$ Fernández (2006), p. 137.

${ }^{74}$ Carreño y Jaraquemada (2010), p. 409.

75 Nogueira (2005), p. 28.
} 
La Ley también es Fuente, pudiendo derogar el precedente judicial. Pero este último no puede derogar la ley. De esta manera se genera un equilibrio entre ambas fuentes. Por su parte, en el Sistema Norteamericano la Corte Suprema y los jueces pueden interpretar la Constitución. Originando argumentos que no pueden ser contradichos por un legislador. Luego, las decisiones de los jueces norteamericanos alcanzan valor de precedente vinculante constitucional. Constituyendo una fuente del Derecho. Nosotros, en cambio, somos herederos o tributarios del Sistema Continental o del Civil Law. El precedente constitucional no es obligatorio o más bien, la jurisprudencia constitucional no es una fuente formal del derecho.

Lo anterior no implica necesariamente desconocer el valor que pudieran tener en nuestro derecho. Eventualmente, estaríamos frente a una jurisprudencia constitucional vinculante y no frente a un precedente constitucional. La diferencia es una cuestión de grado o intensidad. Esto implica que la repetición de criterios normativos contenidos en las sentencias del TCCh, en virtud de las cuales se manifiesta el claro parecer del órgano interpretativo del Texto Fundamental, pueden ser observadas por los jueces y los tribunales del poder judicial, en tanto el precedente debe ser observado. No obstante lo anterior, debe tenerse presente que el control de constitucionalidad implica necesariamente un juicio de razonabilidad, y lo razonable es aquello que se ajusta a la Constitución, no tanto a su letra como a su espíritu, en tanto que lo irrazonable es lo que vulnera la Constitución, es lo inconstitucional ${ }^{76}$. Si bien el principio de razonabilidad no encuentra consagración normativa en nuestra Ley Suprema, estaría implícito en el artículo $7^{\circ}$, con relación al artículo $5^{\circ}$, y 19 , numerales 2, 3, 7, 20, 22 y $26^{77}$.

En el caso norteamericano la declaración de inconstitucionalidad que efectúa la Corte Suprema no provoca la invalidación de la norma como sucede en nuestro sistema con la declaración de inconstitucionalidad por parte del TCCh. La norma se mantiene en un status quo, simplemente no se aplica mientras no existan argumentos en contrarios que modifiquen el precedente establecido. En cambio bajo nuestro modelo eventualmente podrían generarse vacíos normativos mientras el legislador no dicte una nueva norma que venga a regular la materia que antes estaba bajo el amparo de la norma declarada inconstitucional. A nivel normativo no encontramos disposición alguna que

${ }^{76}$ Harol (2001), p. 180.

77 Martínez y ZúNiga (2011), p. 209. 
señale expresamente que las sentencias del TCCh tienen el valor de precedente constitucional.

La norma creada por esta magistratura no tiene la virtud de incorporarse al derecho objetivo, con alcance general y vinculante para todos los poderes públicos. La inobservancia de sus decisiones no se considera como una vulneración al Derecho vigente. Con todo, estimo que se trata en definitiva de una jurisprudencia con escaso valor persuasivo conforme al modelo actual de justicia constitucional, mientras no se realizan las modificaciones normativas en el sentido arriba señalado.

\section{f) Acción o cuestión de Inaplicabilidad}

Se trata de un control jurisdiccional represivo y concreto. Cuyo conflicto gira en torno a la Constitución, el precepto legal impugnado y la aplicación de este último a la gestión pendiente de que se trata. Con efectos relativos que conciernen a las partes del juicio o gestión en que inciden ${ }^{78}$. La decisión jurisdiccional debe recaer en la contrariedad o conformidad con la Constitución que la aplicación del precepto legal impugnado puede tener en el caso concreto y no necesariamente, en su contradicción abstracta y universal con la preceptiva constitucional. De ahí que no todos los preceptos legales declarados inaplicables van a provocar o desembocar necesaria y obligatoriamente en una inconstitucionalidad. En definitiva, se trata de un mecanismo de control de la interpretación de preceptos legales ${ }^{79}$.

El juez a la hora de determinar lo justo para el caso concreto mediante la aplicación de la ley, no sólo la aplica sino que además la debe interpretar. Independiente del tiempo y talento invertido en la producción de normas claras y unívocas, muchas normas jurídicas admiten más de una lectura ${ }^{80}$. Como bien señala Hernán Hormazábal "Cuando un juez aplica un precepto legal a un caso concreto, previamente lo ha de interpretar. No puede haber aplicación

\footnotetext{
${ }^{78}$ En la Comisión de estudios de la Nueva Constitución, Sesión 251, el Ministro de la Corte Suprema José María Eyzaguiirre propuso que existiendo tres declaraciones de inaplicabilidad en el mismo sentido, lo decidido tuviera efectos generales, propuesta que no prosperó, la misma idea fue objeto de debate en el Senado durante la tramitación de la Reforma Constitucional de 2005, ante la Comisión de Constitución, Legislación, Justicia y Reglamento, propuesta por los Ministros del Tribunal Constitucional señores Colombo y Valenzuela, la que también fue rechazada.

${ }^{79}$ Martínez (2011), p. 381.

${ }^{80}$ Zapata (2008), p. 145.
} 
sin una previa interpretación" ${ }^{81}$. La inaplicabilidad implica un juicio de constitucionalidad respecto de la aplicación de un precepto legal al caso particular, lo que se traduce necesariamente en un enjuiciamiento de la interpretación de la norma ${ }^{82}$.

El propio TCCh lo ha señalado reiteradamente “(...) Que en resoluciones anteriores, como las contenidas en los roles $N^{o}$ s. 478, 546, Capitulo I, 473, 517 y 535, de este Tribunal ha precisado en sus considerandos la naturaleza de la actual acción de inaplicabilidad y sus diferencias con la similar prevista en la Carta Fundamental con anterioridad a la reforma del año 2005, destacando especialmente la constatación de que de la simple comparación del texto de la norma actual con el antiguo texto del artículo 80 de la Carta Fundamental, que entregaba esta facultad a la Corte Suprema, se desprende que mientras antes se trataba de una confrontación directa entre la norma legal y la disposición constitucional, ahora se está en presencia de una situación diferente, por cuanto lo que podrá ser declarado inconstitucional, por motivos de forma o fondo, es la aplicación del precepto legal impugnado a un caso concreto, como se dijo, lo que relativiza el examen abstracto de constitucionalidad, marcando asi una clara diferencia con la regulación prevista por el texto constitucional anterior" 33 .

En el mismo sentido en el año 2006 el TCCh señaló “(...) las características y circunstancias especificas y particulares del caso concreto adquieren especial relevancia al momento de resolver esta acción (...), habida consideración de que la decisión judicial recae respecto de la conformidad o contrariedad con la Constitución que la aplicación del precepto legal impugnado pueda tener en cada caso concreto, de modo que no se trata de una declaración abstracta y universal, desvinculada de la gestión judicial que la motiva" ${ }^{44}$.

Así un precepto legal impugnado declarado inaplicable puede ser constitucional en abstracto y resultar inaplicable en otros casos. Constituyendo sólo un indicio de inconstitucionalidad. La sentencia estimatoria de inaplicabilidad constituye un presupuesto procesal de la activación, ya sea acción pública o del actuar de oficio del TCCh. Ahora, si ninguna interpretación posible respecto

\footnotetext{
${ }^{81}$ Hormaź́bal (2006), p. 36.

82 Véase voto concurrente Ministro Correa Sutil. Tribunal Constitucional, Rol No 810-2007-INA, de 24 de enero de 2008.

83 Tribunal Constitucional, Rol No 976-2007- INA, de 26 junio de 2008.

${ }^{84}$ Tribunal Constitucional, Rol No 480-2006- INA, de 27 de junio de 2006 - Rol No 546-2006 INA, de 17 de noviembre de 2006.
} 
de su aplicación resulta compatible con la Ley Suprema, sólo en ese caso será inconstitucional.

\section{g) Acción de inconstitucionalidad}

A diferencia del anterior, estamos frente a un control jurisdiccional represivo y "abstracto" de normas legales. El conflicto gira en torno a la Ley Suprema y el precepto legal declarado previamente inaplicable y cuya sentencia estimatoria, produce efectos temporales ex nuc; efectos personales generales o erga omnes y anulatorios. Invalidado el precepto legal, éste dejará de formar parte del ordenamiento jurídico. En efecto, el TCCh ha señalado "el juicio de inconstitucionalidad expresa una comparación abstracta de dos normas de distinto rango, para constatar su manifiesta incompatibilidad. La ilegitimidad constitucional del precepto legal emana de su propio enunciado, sin referencia a una situación singular" ${ }^{35}$.

Conforme al artículo 93 numeral séptimo de la CPRCh el Tribunal sólo puede declarar inconstitucional un precepto legal ya declarado inaplicable. Posteriormente, no puede extender su declaración de inconstitucionalidad más allá de lo resuelto previamente en las sentencias de inaplicabilidad. Sólo puede considerar las causales en que se sustentó la declaración previa de inaplicabilidad. Es decir, considerar los vicios de inconstitucionalidad que motivaron específicamente la declaración de inaplicabilidad. Lo que se desprende de la expresión "declarado inaplicable de conformidad a lo dispuesto en el numeral anterior".

Sin pretender ahondar sobre el punto, ya que no forma parte de nuestro estudio, se hace difícil pensar en la práctica cómo se puede efectuar un control abstracto, sin tener en consideración los argumentos de la inaplicabilidad ya declarada, sin entrar a consideraciones sobre el fondo de la gestión pendiente. Teóricamente, es abstracto, pero todo parece indicar que es mucho más concreto de lo que pareciera ser. Ambos controles deben proyectarse a la argumentación y hermenéutica constitucional que se desenvuelve en el proceso y se expresa en definitiva en la sentencia de término. Sin embargo, como muy bien anota entre otros Francisco Zúñiga, en general la jurisprudencia del TCCh en sede de inaplicabilidad y de la cuestión de inconstitucionalidad no se aprecia argumentos y uso de reglas que distingan el juicio de legitimidad. No obstante se trata de acciones de distinto alcances ${ }^{86}$. El TCCh en virtud

${ }^{85}$ Tribunal Constitucional, Rol No 1254-2009-INC, de 29 de julio de 2009.

${ }^{86}$ ZÚNiga (2009), p. 36. 
de la acción de inconstitucionalidad no opera, como se sostiene por algunos, como legislador negativo.

$\mathrm{Al}$ efecto ha señalado "que dentro del criterio de interpretación conforme a la Constitución, el respeto hacia las labores que desarrollan tanto el legislador al elaborar las normas de rango legislativo como la judicatura al aplicarlas, obliga al Tribunal Constitucional, en su función de controlar la constitucionalidad de la ley, a buscar, al menos, alguna interpretación del precepto cuestionado que permita armonizarlo con la Carta Fundamental, y sólo en el evento de no ser ello posible, declarar su inconstitucionalidad, criterio que ha seguido en las sentencias roles $N^{o}$ s. 29, 38, 304, 368, 420, 460 y 681, entre otras" ${ }^{87}$.

En definitiva la acción de inconstitucionalidad es de última ratio, cuando se han agotado todos los medios tendientes a buscar una interpretación armónica con la Ley Suprema. Si ello no es posible, entonces el TCCh declarará la inconstitucionalidad del precepto legal tenido previamente, como inaplicable. Generando su decisión, la invalidación de la norma cuestionada.

\section{Efecto invalidatorio de la sentencia de inconstitucionalidad}

Si bien nuestra Constitución al efecto habla de "derogación", pienso que el lenguaje utilizado es poco feliz e impropio. La sentencia estimatoria de inconstitucionalidad tiene efectos personales generales o erga omnes y efectos temporales ex nunc. Opera como una sanción depuradora del ordenamiento jurídico. Dado que, la norma declarada inconstitucional es invalidada. Ésta dejará de formar parte del ordenamiento jurídico nacional. Lo que no es más que una consecuencia de lo dispuesto en el inciso final del artículo $7^{\circ}$ de la CPRC, el TCCh lo que hace en virtud de la declaración, es constatar lo que la propia Norma Fundamental declaro nulo (ipso iure) al omitirse alguno de los requisitos de validez exigidos para la actuación de los órganos del Estado de acuerdo al artículo $7^{\circ}$ inciso primero.

No posee efecto retroactivo, lo que contribuye a reforzar la seguridad jurídica, y se aminoran los problemas que surgen con la inaplicabilidad frente a principio de igualdad ante la ley. De esta manera se protege la buena fe, por lo mismo tal vez ni siquiera habría sido necesario consagrar este efecto a posteriori. Así, el constituyente derivado señala en el artículo 94 inciso tercero "el precepto legal declarado inconstitucional se entenderá derogado desde la publicación en el

${ }^{87}$ Tribunal Constitucional, Rol No 993-2007-INA, de 13 de mayo de 2010. 
Diario Oficial de la sentencia que acoja el reclamo, la que no producirá efecto retroactivo".

La publicación deberá efectuarse dentro de los tres días siguientes a su dictación. Por lo tanto, las situaciones jurídicas, derechos y actos en general consolidados al amparo del precepto legal con anterioridad a la publicación de la sentencia estimatoria no pueden ser atacados como inconstitucionales. Operando respecto de ellos la garantía constitucional del artículo 19 numeral 24. Sin embargo, la invalidación de la norma, genera un vacío o vacancia en tanto no se dicte una nueva disposición que venga a regular la materia de que se trate.

\section{Naturaleza jurídica de la declaración de inconstitucionalidad}

La declaración de inconstitucionalidad constituye una sanción de derecho público por infracción al derecho subjetivo u objetivo de la Ley Fundamental, ya sea de que se trate de vicios de inconstitucionalidad, formal o material o de competencia, de contenido específico de anulabilidad modulada temporalmente con efectos declarativos, invalidando normas del ordenamiento jurídico. Perdiendo la norma declarada inconstitucional la presunción de legitimidad de que gozaba antes de la sentencia estimatoria. Luego no es derogación, ya que la norma declarada inconstitucional pierde validez. Es invalidada, no es admisible la ultra actividad de la misma. No la realiza el legislador y no opera entre normas de igual jerarquía.

Pienso que se trataría más bien de una nulidad de derecho público con efecto particular, sui generis, cuya sentencia declarativa por parte del TCCh no hace más que constatar lo que el constituyente derivado declara nulo ipso iure por haber infringido alguno de los requisitos de validez exigidos para las actuaciones de los órganos del Estado, esto es, investidura regular previa, competencia o procedimiento de conformidad al artículo $7^{\circ}$ inciso primero. Sobre el punto, Sergio Verdugo señala que, la naturaleza de las sentencias que declaran la inconstitucionalidad es una especie de nulidad de Derecho Público atenuada en sus efectos ${ }^{88}$. Discrepo de la opinión del profesor antes citado, la declaración de inconstitucionalidad no es una especie de nulidad de derecho público, es una nulidad de derecho público, una institución no puede ser calificada por sus efectos.

${ }^{88}$ Verdugo (2008), p. 253. 
La declaración de inconstitucionalidad tiene como límite las posiciones, situaciones jurídicas y derechos consolidados ex ante bajo la vigencia del precepto legal ahora inconstitucional. Pero que hasta la publicación de la sentencia estimatoria de inconstitucionalidad gozaba de una presunción de legitimidad y pleno imperio. Lo que está acorde con la exigencia de seguridad jurídica, igualdad ante la ley y del Estado de Derecho vigente.

\section{Conclusiones}

De un primer análisis general de aproximación a la institución de la cosa juzgada constitucional y sus efectos en las sentencias de inaplicabilidad e inconstitucionalidad, podemos extraer las siguientes conclusiones:

1.- En el ámbito del Derecho Constitucional no existe una cosa juzgada en el sentido técnico procesal de la institución. La cosa juzgada constitucional es sui generis en atención a las peculiaridades que presenta y que se han destacado en el presente trabajo. Por ende, tratándose del control constitucional de inaplicabilidad e inconstitucionalidad las sentencias del TCCh no producen el efecto de cosa juzgada en el sentido técnico procesal de la institución. Hay una cosa decidida, sui generis, la que no responde a los mismos objetivos, características y finalidades de la cosa juzgada en el sentido procesal civil, apartándose de las categorías tradicionales del Derecho.

2.- Los efectos de la cosa juzgada constitucional sui generis, difieren sustancialmente de los efectos de la cosa juzgada en materia procesal civil. Con todo, las sentencias del TCCh emanadas del control de inaplicabilidad e inconstitucionalidad producen el efecto de una cosa juzgada formal, no material. Tratándose de la inconstitucionalidad, si bien lo decido en virtud de la sentencia no puede volver a discutirse no se genera a consecuencia de la cosa juzgada material sino más bien, al efecto que se produce por la invalidación de la norma del ordenamiento jurídico. No es posible jurídicamente hablando alegar la acción o excepción de cosa juzgada respecto de una norma que no existe. Ahora si se plantea nuevamente el asunto ya decidido por sentencia firme y ejecutoriada, sería más bien un problema de Iura novit curia.

3.- La función del Tribunal no es la de reemplazar al legislador, el que goza de libertad política. Luego, no es la de fijar la mejor interpretación de cada precepto constitucional. Sino sólo eliminar aquellas incompatibles con el Texto Fundamental. Por lo tanto la validez de la ley ha de mantenerse cuando su texto no impida una interpretación acorde a la Constitución. Tampoco le corresponde 
la revisión de la aplicación del derecho realizada por los jueces, sino sólo si esa aplicación se adecua a la Ley Fundamental.

4.- La sentencia estimatoria de inaplicabilidad no produce efecto alguno en la gestión pendiente que se sigue ante un tribunal ordinario o especial. Dado que el precepto legal impugnado en el evento que se acoja, no es aplicable. El efecto lo produce en el juicio de inaplicabilidad seguido ante el TCCh. Situación que queda aún más patente cuando se trata de la sentencia estimatoria de inconstitucionalidad. Ya que la norma cuestionada es invalidada, dejando de formar parte del ordenamiento jurídico.

5.- La declaración de inconstitucionalidad provoca la invalidez del precepto legal declarado previamente inaplicable por haberse omitido alguno de los requisitos para la validez de las actuaciones de los órganos del Estado, no la derogación del precepto legal. La facultad de declarar la inconstitucionalidad de una ley con efectos generales y obligatorios para todas las autoridades constituye una interferencia al poder legislativo. La facultad legislativa, creadora de Derecho, es exclusiva del pueblo o sus representantes debidamente electos. Ellos son los llamados a hacer las normas con sustancia legislativa y efectos erga omnes. Son la máxima institución representativa del pueblo dentro de un Estado y tienen la calidad o estatus de constituyente derivado.

6.- Nuestro modelo de justicia constitucional separado del Poder Judicial carece de reglas claras que regulen la jerarquía y relaciones entre la judicatura constitucional y la ordinaria, lo que genera criterios muy dispares entre sus fallos. En efecto, de la simple lectura de las sentencias que resuelven la gestión pendiente, habiéndose pronunciado el TCCh, ya sea acogiendo o desestimando la inaplicabilidad, en ninguno de los considerando se hace la más mínima alusión a los fundamentos y razonamientos tenido en cuenta por el Intérprete Constitucional. Incluso fallándose en sentido contrario a la determinación del Intérprete Supremo. Cuestión que se produce no sólo a propósito de requerimientos de inaplicabilidad a petición de parte sino también de oficio por el juez que conoce del asunto. Sea que se trate de un tribunal ordinario o especial, dejando en entredicho la fuerza vinculante y el efecto de sus sentencias.

\section{Bibliografía CitADA}

Aldunate Lizana, Eduardo (1993): "Jurisdicción Constitucional y Cosa Juzgada Constitucional”, en Revista Chilena de Derecho, (Vol. 20 No 2-3), pp. 355-359. 
Aldunate Lizana, Eduardo (1997): "El Derecho Procesal Constitucional desde la Perspectiva de la Teoría Constitucional", en Revista de Derecho de la Universidad Católica de Valparaíso, (No 18), pp. 87-99.

Caamaño Domínguez, Francisco; Medina Guerrero, Manuel; Gómez Montoro, Ángel J. (1997): Jurisdicción y procesos constitucionales (Madrid, McGrawHill/interamericana de España, S.A.).

Calderón Cuadrado, María Pía (2008): Tutela Civil declarativa. De la acción a la sentencia de pura declaración (Valencia, Tirant lo Blanch).

Carreño Pavez, Gonzalo y Jaraquemada Robledo, Jorge (2010). "La Fuerza vinculante de las sentencias constitucionales y el reconocimiento de derechos fundamentales. A propósito de la ley sobre regulación de la fertilidad", (30 de marzo de 2011). Disponible en: http://www.scielo.cl/scielo.php?pidS0718-34372010000200011\&Script_sci-arttext.

Carnelutti, Francisco (1994): Sistema de Derecho Procesal Civil (Buenos Aires, UTEHA), $\mathrm{t}-1$.

Casal Hernández, Jesús María (2004): "Cosa juzgada y efecto vinculante en la justicia constitucional", en Anuario de Derecho Constitucional Latinoaméricano, (No 20041), pp. $299-325$.

Casal Hernández, Jesús María (2006): Constitución y Justicia Constitucional (Caracas, Universidad Católica Andrés Bello).

Colombo Campbell, Juan (1980). La jurisdicción, el acto jurídico procesal y la cosa juzgada en el Derecho Chileno (Santiago, Editorial Jurídica de Chile).

Colombo Campbell, Juan (2005): "Las sentencias constitucionales: tipología y efectos", en Humberto Nogueira Alcalá (coord.), Jurisdicción Constitucional en Chile y América Latina. Presente y Prospectiva (Santiago, Editorial LexisNexis).

Colombo Campbell, Juan (2004): Derecho Procesal Constitucional. Enfoques conceptuales y caracterización del Derecho Procesal Constitucional a principios del siglo XXI (Santiago, Tribunal Constitucional).

Couture, Eduardo (2010): Fundamentos del Derecho Procesal Civil, 4a edic. (Buenos Aires, Edit. IB de F).

Chiovenda, Giuseppe (1954): Instituciones de Derecho Procesal Civil (Madrid, Edit. Revista de Derecho Privado), t. III.

De La Oliva Santos, Andrés (1991): Sobre la cosa juzgada (Madrid, Ramón Areces). 
De La Oliva Santos, Andrés (2005): Objeto del proceso y cosa juzgada en el proceso civil (Madrid, Thomson Civitas).

Dougnac, Antonio (1996): "La cosa juzgada en el derecho procesal del reino de Chile”, en Revista de Estudios Históricos Jurídicos, (Vol. 18), pp. 169-186.

Errázuriz Gatica, Juan Miguel y Otero Alvarado, Jorge Miguel (1989). Aspectos procesales del recurso de protección (Santiago, Editorial Jurídica de Chile).

FERnÁNDEZ, Miguel Ángel (2006): "Las sentencias del Tribunal Constitucional, su eventual carácter vinculante y la inserción en las fuentes del Derecho", en Revista de Estudios Constitucionales, (Año 4, No 2), pp. 125-149.

Fernández, Tomás Ramón y García de Enterría, Eduardo (1989). Curso de Derecho Administrativo I, 5 a edic. (España, Editorial Civitas).

GANDUlfo R., Eduardo (2009). "Sobre preclusiones procesales en el derecho chileno en tiempo de reformas. Ensayo de una teoría general desde un enfoque valorativo jurídico, en Revista Ius et Praxis (Año 15 No 1), pp. 121-189.

Gómez Bernalez, Gastón (2005): "La reforma constitucional a la jurisdicción constitucional”, en Francisco Zúñiga Urbina (Coord.) Reforma Constitucional (Santiago, LexisNexis).

Grande Seara, Pablo (2008). La extensión subjetiva de la cosa juzgada en el proceso civil (Valencia, Tirant lo Blanch).

Guerrero, Gonzalo (2005). "La fuerza vinculante de las sentencias del Tribunal Constitucional Chileno. Una aproximación desde la reforma constitucional de 2005" (19 de marzo de 2011). Disponible en: http://www.congresoconstitucional.cl.

Haro, Ricardo (2001): "La razonabilidad y las funciones del control”, en Ius et Praxis, No 2, Vol. 7, pp. 179-186.

HernándeZ, Rubén (2004): "La vinculatoriedad de las resoluciones de la Sala Constitucional", en Revista Iberoamericana de Derecho Procesal Constitucional (Año 2004 No 1 enero-junio), pp. 45-60.

Legare, Santiago y Rivera, Julio (2006): "Naturaleza y dimensiones del Stare Decisis", en Revista Chilena de Derecho (Vol. 33, No 1), pp. 109-124.

López Medina, Diego (2000): El derecho de los jueces (Bogotá, Ediciones Uniandes legis).

Martínez Estay, José Ignacio (2005): "Recurso de inaplicabilidad, Tribunal Constitucional y juez ordinario en la reforma constitucional”, en Humberto 
Nogueira Alcalá (Coord.), La Constitución Reformada de 2005 (Santiago, Librotecnia), pp. 457-472.

Martínez EstaY, José Ignacio y ZúNiga Urbina, Francisco (2011): “El principio de la razonabilidad en la jurisprudencia del Tribunal Constitucional", en Revista de Estudios Constitucionales (Año 9, No 1), pp. 199-296.

Martínez Estay, José Ignacio (2011): "La cuestión de inaplicabilidad como mecanismo de control de la interpretación de preceptos legales", en Jaime Arancibia Mattar, José Ignacio Martínez y Alejandro Romero Seguel (Coordinadores), Colección Estudios de Derecho Público. Litigación Pública, Universidad de los Andes (Santiago, Abeledo Perrot. LegalPublishing), pp. 377-396.

Muerza Esparza, Julio (2001): "De las actuaciones judiciales", en AA.VV. Comentarios a la ley de enjuiciamiento civil, (Navarra, Editorial Aranzadi), vol. I.

Nieva Fenoll, Jordi (2010): La cosa juzgada. El fin de un mito (Santiago, Editorial Abeledo Perrot. LegalPublishing).

Nogueira Alcalá, Humberto (2004): "Consideraciones sobre las sentencias de los Tribunales Constitucionales y sus efectos en América del Sur”, en Revista Ius et Praxis, (Año 10, No 1), pp. 113-158.

Nogueira Alcalá, Humberto (2005): "El control represivo concreto y abstracto de inconstitucionalidad de leyes en la reforma constitucional 2005 de las competencias del Tribunal Constitucional y los efectos de sus sentencias", en A.A.V.V. La Constitución Reformada de 2005 (Santiago, Librotecnia) pp. 421-455.

PiCA FlORES, Rodrigo (2010, a): "El procedimiento correspondiente al proceso de inaplicabilidad por inconstitucionalidad en la Ley Orgánica Constitucional del Tribunal Constitucional", en Humberto Nogueira Alcalá (coord.), Temas de Derecho procesal Constitucional. Reflexiones juridicas sobre competencias del Tribunal Constitucional y la nueva LOC del Tribunal Constitucional (Santiago, Librotecnia), pp. 237-261.

Pica Flores, Rodrigo (2010, b): Control jurisdiccional de Constitucionalidad de la ley en Chile. Los procesos de inconstitucionalidad y de inaplicabilidad por inconstitucionalidad de competencia del Tribunal Constitucional. (Santiago, Ediciones Jurídicas de Santiago).

Ramos Méndez, Francisco (1999): El sistema procesal español, 3a edic. (Barcelona, Editorial J. Ma Bosch). 
Ríos Álvarez, Lautaro (2002): "El control difuso de constitucionalidad de la ley en la República de Chile", en Revista de Derecho Pontificia Universidad Católica de Valparaíso (No 23), pp. 39-67.

Ríos Álvarez, Lautaro (2005): "Trascendencia de la reforma constitucional en la fisonomía y las atribuciones del Tribunal Constitucional”, en Revista Estudios Constitucionales, (Año 3, No 1), pp. 73-95.

Ríos Álvarez, Lautaro (2010) "La sentencia de inconstitucionalidad en la reforma de la L.O.C. del Tribunal Constitucional”, en Humberto Nogueira Alcalá (coord.), Temas de Derecho procesal Constitucional. Reflexiones jurídicas sobre competencias del Tribunal Constitucional y la nueva LOC del Tribunal Constitucional (Santiago, Librotecnia), pp. 27-63.

Romero Seguel, Alejandro (2002). La cosa juzgada en el proceso civil chileno: Doctrina y jurisprudencia (Santiago, Editorial Jurídica de Chile).

Soto KLoss, Eduardo (1982). El recurso de protección (Santiago, Editorial Jurídica de Chile)

Serra Domínguez, Manuel (1969): Intervención de terceros en el proceso Estudios de Derecho Procesal. (Barcelona, Edit. Ariel).

Vallinés García, Enrique (2004): La preclusión en el proceso civil (Madrid, Editorial Thomson-Civitas).

Verdugo Ramírez, Sergio (2008) "La declaración de inconstitucionalidad de las leyes como control represivo abstracto. Una especie de nulidad de derecho público atenuada en sus efectos", en Revista Actualidad Jurídica, (No 18), pp. 247-297.

Verdugo Ramírez, Sergio (2011) "El nuevo round entre el TC y los Tribunales Superiores: Dificultad ineludible del modelo de cohabitación Kelseniano", (22 de diciembre 2011). Disponible en www.diarioconstitucional.cl.

Zapata Larraín, Patricio (2008): Justicia Constitucional. Teoría y Práctica en el Derecho Chileno y Comparado, (Chile, Editorial Jurídica de Chile).

ZÚNIGga Urbina, Francisco (2005): "Control concreto de constitucionalidad: recurso de inaplicabilidad y cuestión de constitucionalidad en la reforma constitucional", en A.A.V.V. La Constitución Reformada de 2005 (Santiago, Librotecnia) pp. 473- 494.

ZúñIga Urbina, Francisco (2010): "La relación Tribunal Constitucional - Tribunales del fondo y los efectos de las sentencias de inaplicabilidad acerca de los presupuestos de la acción", en Humberto Nogueria Alcalá (coord.) Temas de Derecho Procesal Constitucional. Reflexiones juridicas sobre competen- 
cias del Tribunal Constitucional y la nueva LOC del Tribunal Constitucional (Santiago, Edit. Librotecnia), pp. 263-353.

Zúñiga Urbina, Francisco (2009). "Cuestión de inconstitucionalidad. Doctrina y jurisprudencia del Tribunal Constitucional”, (24 de abril de 2010). Disponible en http://www.derechouc.cl/jornadas/?m-200911\&paged-3.

\section{Normas Jurídicas CitadAs}

Ley No 20.050, sobre Reforma Constitucional, Diario Oficial, 26 de agosto de 2005.

Ley No 20.381, Orgánica Constitucional del Tribunal Constitucional, Diario Oficial, 28 octubre de 2009.

D.F.L. No 5 del Ministerio Secretaria General de la Presidencia, Fija Texto refundido, Coordinado y Sistematizado de la L.O.C. No 17.997 del Tribunal Constitucional, Diario Oficial, 10 de agosto de 2010.

Ley No 7135, sobre Jurisdicción Constitucional de Costa Rica, de 11 de octubre de 1989.

Constitución Política de la República de Perú, de 1993.

Constitución Política de la República de Colombia, de 4 de julio de 1991.

Constitución Política de la República de Ecuador, de 20 de octubre de 2008.

Constitución Política de la República de Venezuela, de 15 de diciembre de 1999.

Constitución Política de la República Federal Alemana, de 1949.

Constitución Política de la República de Italia, de 1 de enero de 1948.

Constitución Política de España, de 29 de diciembre de 1978.

\section{JuRisprudencia Citada}

Sentencia Corte Suprema, 6 de abril de 1939, RDJ, t. 37, sec. 1a, p. 1.

Sentencia Corte Suprema, 5 de noviembre de 1970, RDJ, t. 67, sec. $1^{\text {a }}$, p. 505.

Sentencia Corte Suprema, Rol No 12.684, de 04 de mayo de 1990.

Tribunal Constitucional, Rol No 480-2006 INA, de 27 de junio de 2006.

Tribunal Constitucional, Rol No 546-2006 INA, de 17 de noviembre de 2006.

Tribunal Constitucional, Rol No 591-2006-INC, de 11 de enero de 2007. 
Tribunal Constitucional, Rol No 681-2006-INC, de 26 de marzo de 2007. Tribunal Constitucional, Rol No 535-2006-INA, de 8 de mayo de 2007.

Tribunal Constitucional, Rol No 558-590-2006-INC, de 5 de junio de 2007. Tribunal Constitucional, Rol No 623-2006-INA, de 10 de septiembre de 2007.

Tribunal Constitucional, Rol No 781-2007-INA, de 27 de septiembre de 2007.

Tribunal Constitucional, Rol No 608-2006-INA, de 2 de octubre de 2007.

Tribunal Constitucional, Rol No 979-2007-INA, de 29 de noviembre de 2007.

Tribunal Constitucional, Rol No 810-2007-INA, de 24 enero de 2008.

Tribunal Constitucional, Rol No 976-2007- INA, de 26 junio de 2008.

Tribunal Constitucional, Rol No 1311-2009- INA, de 2 de abril de 2009.

Tribunal Constitucional, Rol No 1173-2008-INC, de 16 de abril de 2009.

Tribunal Constitucional, Rol No 1254-2009-INA, de 29 de julio de 2009.

Tribunal Constitucional, Rol No 1254-2009-INC, de 29 de julio de 2009.

Tribunal Constitucional, Rol No 993-2007-INA, de 13 de mayo de 2010.

Tribunal Constitucional, Rol No 1801-2010-INA, de 12 de abril de 2011.

Sentencia Corte Apelaciones Valparaíso, Rol No 300-2010, de 6 de mayo de 2011.

Sentencia Corte Suprema, Rol No 4518-2011, de 30 de noviembre de 2011. 